\title{
Gold Nanoparticles Promote Oxidant-Mediated Activation of NF- $\kappa$ B and 53BP1 Recruitment-Based Adaptive Response in Human Astrocytes
}

\author{
Jennifer Mytych, ${ }^{1}$ Anna Lewinska, ${ }^{2}$ Jacek Zebrowski, ${ }^{3}$ and Maciej Wnuk ${ }^{1}$ \\ ${ }^{1}$ Department of Genetics, University of Rzeszow, Rejtana 16C, 35-959 Rzeszow, Poland \\ ${ }^{2}$ Department of Biochemistry and Cell Biology, University of Rzeszow, Zelwerowicza 4, 35-601 Rzeszow, Poland \\ ${ }^{3}$ Department of Plant Physiology, University of Rzeszow, Werynia 502, 36-100 Kolbuszowa, Poland \\ Correspondence should be addressed to Maciej Wnuk; mawnuk@gmail.com
}

Received 6 May 2015; Accepted 11 June 2015

Academic Editor: Jinsong Ren

Copyright (C) 2015 Jennifer Mytych et al. This is an open access article distributed under the Creative Commons Attribution License, which permits unrestricted use, distribution, and reproduction in any medium, provided the original work is properly cited.

\begin{abstract}
Nanogold-based materials are promising candidate tools for nanobased medicine. Nevertheless, no conclusive information on their cytotoxicity is available. In the present study, we investigated the effects of gold nanoparticles (AuNPs) on human astrocytes in vitro. Nanogold treatment in a wide range of concentrations did not result in cytotoxicity. In contrast, nanogold provoked changes in the astrocyte cell cycle and induced senescence-associated $\beta$-galactosidase activity. AuNPs promoted oxidative stress and caused activation of NF- $\kappa \mathrm{B}$ pathway. After nanogold treatment, an inverse correlation between the formation of $53 \mathrm{BP} 1$ foci and micronuclei generation was observed. The robust 53BP1 recruitment resulted in reduced micronuclei production. Thus, nanogold treatment stimulated an adaptive response in a human astrocyte cell.
\end{abstract}

\section{Introduction}

Gold nanoparticles (AuNPs) of high chemical stability, wellcontrolled size, and surface functionalization are considered promising tools for nanobased medicine, including biosensors, bioimaging, photothermal therapy, and targeted drug delivery $[1-3]$. The delivery of therapeutic biomolecules and transgenes is particularly challenging in the central nervous system (CNS) due to blood-brain barrier (BBB) formed by endothelial cells, pericytes, astrocytes, and microglial cells, which can be to some extent overcome by the use of nanogold facilitating the treatment and diagnosis of neurological disorders [3-6]. Glucose-coated gold nanoparticles can selectively cross human brain endothelium in vitro and localize in astrocytes [5]. Although the gold core is inert and nontoxic and AuNPs are thought to be highly biocompatible [7], they may also interact with biological material and have biological effects, which needs to be carefully addressed $[8,9]$.

Conflicting results on nanogold-mediated toxicity in diverse mammalian cells in vitro have been reported [7, 1018]. $1.4 \mathrm{~nm}$ AuNPs were found to be much more toxic than
$15 \mathrm{~nm}$ AuNPs to connective tissue fibroblasts, epithelial cells, macrophages, and melanoma cells [10]. In contrast, $18 \mathrm{~nm}$ AuNPs were not toxic to human leukemia cells [7] and 60 $\mathrm{nm}$ AuNPs were not toxic to murine macrophages [11]. As the response to nanogold is affected by the nanoparticle size and the cell type examined, the effects of AuNPs should be also evaluated in every cell type to be used for nanogold-based technologies, especially in the brain.

Data on nanoparticle effects in the brain tissue and cells both in vitro and in vivo are scarce and two main features were observed, namely, nanoparticle-mediated oxidative stress and inflammatory response [19-23]. A mixed primary cell model consisting mainly of neurons and astrocytes and a minor proportion of oligodendrocytes was used to study nanoparticle-mediated neurotoxicity [22]. In contrast to nontoxic $20 \mathrm{~nm}$ gold nanoparticles, $20 \mathrm{~nm}$ silver nanoparticles were found to be effective against primary mixed neural cell cultures [22]. AgNPs (up to $20 \mu \mathrm{g} / \mathrm{mL}$ ) stimulated calcium dysregulation and reactive oxygen species (ROS) formationbased response [22]. Moreover, astrocytes were found to be much more sensitive to nanosilver treatment compared with 
neurons and AgNPs were mainly taken up by astrocytes and not by neurons [22].

As available information on nanogold-mediated effects on a human astrocyte cell is limited, we decided to evaluate AuNP-associated response in human astrocytes in vitro; we especially focused on AuNP effects on cyto- and genotoxicity, as well as nanogold-induced oxidative stress and NF- $\kappa \mathrm{B}$ pathway.

\section{Materials and Methods}

2.1. Chemicals. Gold nanoparticles (AuNPs) were purchased from Sigma (765449, $5 \mathrm{~nm}$ diameter, carboxylic acid functionalized, PEG 5000 coated, OD $=50$, and dispersion in $\mathrm{H}_{2} \mathrm{O}$, Poznan, Poland) and phosphate-buffered saline (PBS) was obtained from Gibco, Invitrogen Corporation, Grand Island, NY, USA. All other reagents, if not mentioned otherwise, were purchased from Sigma (Poznan, Poland) and were of analytical grade.

2.2. Characterization of AuNPs: AFM. Commercially available gold nanoparticles (765449, Sigma) were characterized using atomic force microscopy (AFM). The shape, size distribution, tendency to agglomerate, and concentration in suspension of AuNPs were evaluated using Bioscope Catalyst II atomic force microscope equipped with Nanoscope V controller (Veeco, Santa Barbara, CA, USA). AuNPs were suspended in distilled water and the suspension was spread out over the surface of freshly cleaved mica (V1 grade, Ted Pella Inc., USA). The particles were then allowed to adhere to the mica surface as a result of drying out under gentle $\mathrm{N}_{2}$ stream. Topography AFM imaging of the preparations with deposited gold nanoparticles was carried out in the Peak Force Tapping mode (amplitude set point $100 \mathrm{nN}$, gain 0.8) using Bruker's sharp silicon nitride SNL-10 A probes of nominal spring constant $k=0.35 \mathrm{~N} / \mathrm{m}$ and $2 \mathrm{~nm}$ nominal tip radius. Height sensor and Peak Force error images were collected at the scan rate of $0.35 \mathrm{~Hz}$ and at the resolution of 768 pixels per line using Nanoscope (v. 8.15sr3, Bruker) software. Images were processed and analyzed for the particle height and the size distribution by means of Nanoscope Analysis (v. 1.50, Bruker Corporation, Germany) software. The concentration of AuNPs in suspension was also evaluated using atomic force microscopy. A drop $(1 \mu \mathrm{L})$ of the nanoparticle suspension was added to a drop $(1 \mu \mathrm{L})$ of $10 \%$ Tween-20 previously deposited on freshly cleaved piece of mica. As a result of the fusion of both portions of liquids, the suspension with reduced surface tension easily spread over the mica substrate allowing for approximately equal deposition of the nanoparticles throughout mica surface area (c. $100 \mathrm{~mm}^{2}$ ). The nanoparticles were allowed to deposit on the mica substrate during subsequent drying at nitrogen atmosphere and occasional gentle swaying. The preparations with adhered AuNPs were then imaged using AFM. The height sensor images were collected for surface area of $10 \mu \mathrm{m} \times 10 \mu \mathrm{m}$ taken at 4 random locations for two different samples. The images were processed using Nanoscope Analysis software (v. 1.50, Bruker) and exported as TIFF-extension files for the particle counting with ImageJ v. 1.45 software. The amount of detected particles multiplied by the ratio of the mica sheet area to the real area of the image was considered as the estimation of the nanoparticle number in the drop of applied nanoparticle suspension.

2.3. Cell Culture. Gibco Human Astrocytes were obtained from Life Technologies (N7805-100, Warsaw, Poland). The cells were cultured at $37^{\circ} \mathrm{C}$ in Gibco Astrocyte Medium (A1261301, Dulbecco's Modified Eagle's Medium (DMEM), N-2 Supplement, and One Shot Fetal Bovine Serum (FBS)) in a humidified atmosphere in the presence of $5 \% \mathrm{CO}_{2}$. According to the manufacturer's instructions, Geltrex matrixcoated plates (A14132) and 3000 cells per well in a 96-well plate or 5000 cells per well in a 4 -well plate were used. Astrocytes were cultured for $24 \mathrm{~h}$, medium was then discarded and fresh medium containing $1.1 \times 10^{9}, 1.1 \times 10^{10}, 1.1 \times 10^{11}$, and $5.5 \times 10^{11}$ AuNPs/mL that corresponds to $1.4,14,140$, and $700 \mathrm{ng} / \mathrm{mL}$ [17] was added and cells were cultured for another $96 \mathrm{~h}$. Every 48 h, the medium supplemented with AuNPs was replaced by a fresh one.

2.4. Cytotoxicity, Cell Cycle Analysis, and SA- $\beta$-gal Activity. After $96 \mathrm{~h}$ treatment with gold nanoparticles, acridine orange-ethidium bromide staining was used to assess cytotoxicity [24]. Cell cycle analysis was conducted using an In Cell Analyzer 2000 (GE Healthcare, UK) equipped with a high performance CCD camera [25]. Senescence-associated $\beta$-galactosidase activity (SA- $\beta$-gal) was measured according to Mytych et al. [26].

2.5. Oxidative Stress. After $96 \mathrm{~h}$ treatment with gold nanoparticles, the steady-state level of reactive oxygen species (ROS) inside a cell was measured using redox-sensitive fluorogenic probe $2^{\prime}, 7^{\prime}$-dichlorodihydrofluorescein diacetate $\left(\mathrm{H}_{2} \mathrm{DCF}\right.$ DA) and imaging cytometry (In Cell Analyzer 2000 equipped with a high performance CCD camera, GE Healthcare, UK). Briefly, the cells were incubated in PBS containing $5 \mu \mathrm{M}$ $\mathrm{H}_{2}$ DCF-DA for $15 \mathrm{~min}$ in the dark, cells were then washed, and intracellular fluorescent signals were acquired and quantified using In Cell Analyzer 2000 Software (GE Healthcare). The level of ROS is presented as relative fluorescence units (RFUs).

2.6. NF- $\kappa B$ Activation. After $96 \mathrm{~h}$ treatment with gold nanoparticles, immunostaining protocol was used as previously described [26]. Briefly, fixed cells were incubated with a primary antibody anti-p65 (1:100) (Abcam, UK) and a secondary antibody conjugated with FITC $(1: 1000)$ (Pierce, UK). Nuclei were visualized with Hoechst 33342. Digital cell images were captured with an In Cell Analyzer 2000 (GE Healthcare, UK) equipped with a high performance CCD camera. The NF- $\kappa \mathrm{B}$ p 65 nuclear-positive cells were scored [\%].

2.7. Micronuclei Production. After 96 h treatment with gold nanoparticles, a BD Gentest Micronucleus Assay Kit with the standard protocol was used [26].

2.8. 53BP1 Immunostaining. After $96 \mathrm{~h}$ treatment with gold nanoparticles, immunostaining protocol was used as 


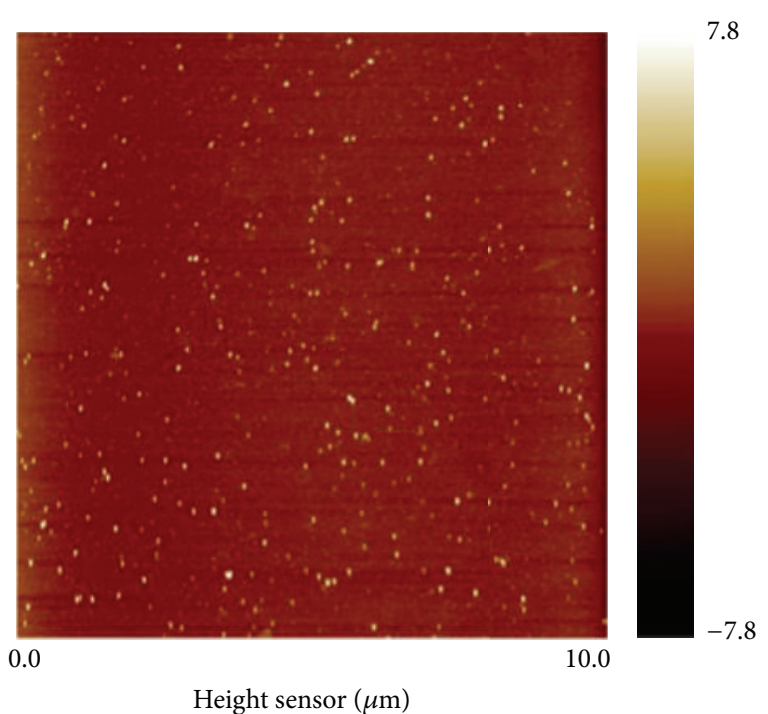

(a)

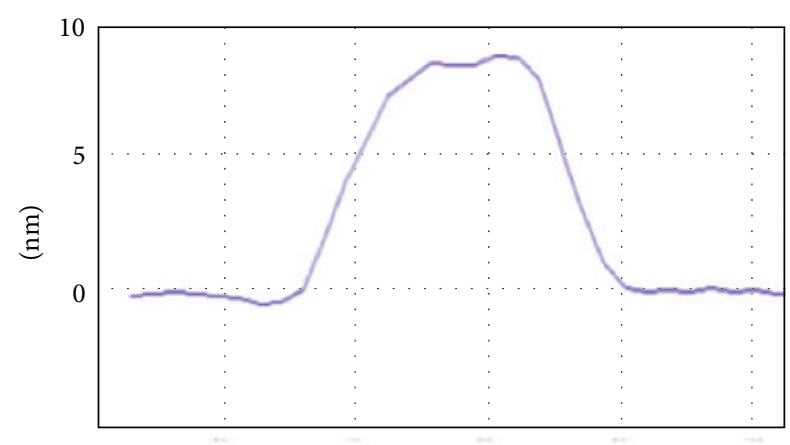

(c)

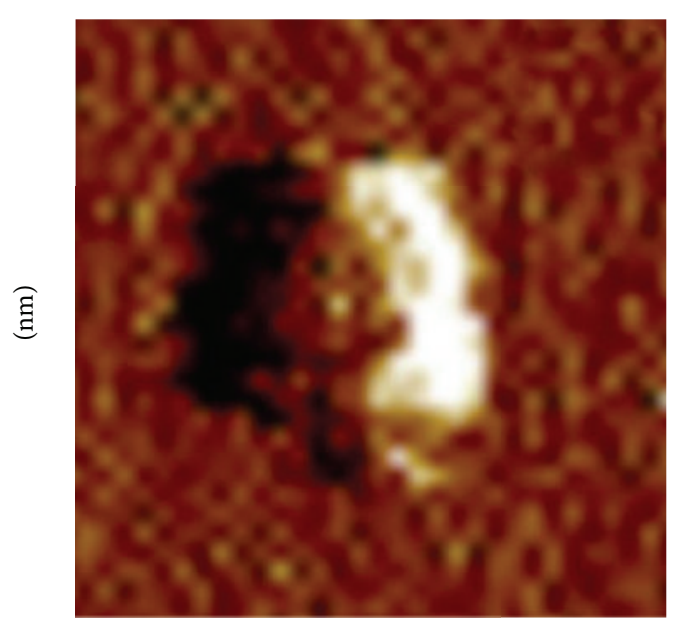

(b)

\begin{tabular}{|c|c|c|c|c|c|}
\hline & \multicolumn{5}{|c|}{ Particle size interval (nm) } \\
\hline & $<\overline{0} . \overline{5}$ & $\overline{0.5-\overline{1.0}}$ & $-\overline{1-\overline{5}}-$ & $-\overline{5-1} \overline{0}-$ & $>10^{-}$ \\
\hline Frequency & 0.663 & 0.227 & 0.074 & 0.028 & 0.007 \\
\hline
\end{tabular}

(d)

Figure 1: Characteristics of gold nanoparticles (AuNPs) using atomic force microscopy (AFM). (a) Representative height sensor image of AuNPs deposited on nonfunctionalized mica showing their diversity in size and lack of the tendency for particle agglomeration in water suspension. (b) Typical shape of a gold nanoparticle obtained in Peak Force mode at high-resolution imaging (the particle height equal to c. $9.5 \mathrm{~nm}$ ). (c) A height profile of an individual AuNP used for determination of the particle size. (d) The distribution of nanoparticle size.

previously described [26]. Briefly, fixed cells were incubated with a rabbit polyclonal antibody against 53BP1 $(1: 200)$ (Novus Biologicals, Poland) and with a FITC-conjugated, secondary polyclonal antibody against rabbit IgG $(1: 200)$ (BD Biosciences, Germany). Nuclei were visualized with Hoechst 33342. Digital cell images were captured with an In Cell Analyzer 2000 (GE Healthcare, UK) equipped with a high performance CCD camera. The cells with $0,1,2,3$, and more than 3 53BP1 foci were scored [\%].

2.9. Statistical Analysis. The results represent the mean \pm SD from at least three independent experiments. Statistical significance was assessed by 1-way ANOVA using GraphPad Prism 5, with Dunnett's multiple comparison test.

\section{Results}

As gold nanoparticles were commercially purchased, AuNPs were characterized for selected physical properties before the analysis of their effects on human astrocytes. Atomic force microscopy (AFM) imaging showed that AuNPs suspended in water were capable of dispersing on mica substrate without tendency for agglomerating (Figure 1(a)). This property was likely to be associated to some extent with commercial functionalizing of the AuNP with polyethylene glycol (PEG).

The AFM images also showed the high purity of AuNP samples, as no contamination with microsized components has been detected. The gold nanoparticles showed rather irregular than spherical shape as visualized at high resolution in the Peak Force Tapping mode (Figure 1(b)). The crosssectional height profile on $z$-axis (Figure 1(c)) was the base for determination of the individual particle size at the resolution below $0.3 \mathrm{~nm}$. The frequency of AuNP size distribution for a representative particle sample (Figure 1(d)) indicated rather high dispersion in the particle size below $10 \mathrm{~nm}$ with large prevalence of fractions below $1 \mathrm{~nm}$ in size. The estimated AuNP concentration was approximately $1.1 \times 10^{11}$ particles/ $\mu \mathrm{L}\left(1.1 \times 10^{14}\right.$ particles $\left./ \mathrm{mL}\right)$. Moreover, we have compared our 
AFM-based calculations with absorption cross section-based calculations using the formula

$$
\mathrm{OD}=\log (e) \times \text { absorption cross section } \times\left(\frac{N}{V}\right) \times l,
$$

where $\log (e)=0.434568904$, absorption cross section for $5 \mathrm{~nm}$ AuNPs is $6 \times 10^{-14} \mathrm{~cm}^{2}, N / V$ is the number of nanoparticles per volume, and $l$ is the length of the cuvette, $1 \mathrm{~cm}$.

We have obtained that $N / V=1.9 \times 10^{15}$ particles $/ \mathrm{mL}$ that differs from that obtained after AFM-based calculations $\left(1.1 \times 10^{14}\right.$ particles $\left./ \mathrm{mL}\right)$. As we have already detected a large fraction of AuNPs of diameter lower than $0.5 \mathrm{~nm}$ in the solution, such discrepancies are not so surprising. We believe that our AFM-based calculations are more accurate and adequate in this particular case.

As nanogold in a range of concentrations from 36 to $1000 \mathrm{ng} / \mathrm{mL}$ was screened for cytotoxic effects in different mammalian cell lines [14], we used AuNP concentrations ranging from 1.4 to $700 \mathrm{ng} / \mathrm{mL}$ that corresponds to $1.1 \times 10^{9}-$ $5.5 \times 10^{11} \mathrm{AuNPs} / \mathrm{mL}$ [17]. As a negative control, supernatant of AuNP after centrifugation was used. We were not able to observe any differences compared to control conditions (data not shown). Cytotoxic potential of AuNPs was minimal as estimated using acridine orange-ethidium bromide staining (Figure 2(a)).

AuNP treatment resulted in astrocyte cell death in up to $5 \%$ of total population examined (Figure $2(\mathrm{a})$ ). In contrast, nanogold promoted changes in the astrocyte cell cycle (Figure 2(b)). After AuNP treatment, cells preferentially accumulated in the $\mathrm{G} 2 / \mathrm{M}$ phase of the cell cycle. The percentage of cells in the G2/M phase of the cell cycle increased from $38 \%$ (control conditions) to approximately 52\% (treatment with $1.1 \times 10^{11}$ AuNPs $/ \mathrm{mL}$ ) and $50 \%$ (treatment with $5.5 \times$ $10^{11}$ AuNPs/mL) (Figure 2(b)). Moreover, nanogold caused an increase in the level of SA- $\beta$-gal-positive cells, which may suggest that AuNP may stimulate stress-induced premature senescence (SIPS) in human astrocytes (Figure 2(c)). Treatments with $1.1 \times 10^{11}$ AuNPs/mL and $5.5 \times 10^{11} \mathrm{AuNPs} / \mathrm{mL}$ resulted in $55 \%$ and $75 \%$ increase in SA- $\beta$-gal-positive cells compared with control, respectively, $P<0.001$ (Figure $2(\mathrm{c})$ ).

Nanogold also induced oxidative stress in human astrocytes (Figure 3(a)).

The level of reactive oxygen species (ROS) was increased by $40 \%$ and $34 \%$ after treatments with $1.1 \times 10^{11} \mathrm{AuNPs} / \mathrm{mL}$ and $5.5 \times 10^{11}$ AuNPs/mL compared with control, respectively, $P<0.001$ (Figure 3(a)). AuNPs also provoked NF- $\kappa \mathrm{B}$ activation because $\mathrm{p} 65$ nuclear signals were elevated after gold nanoparticle treatment (Figure 3(b)). Treatments with $1.1 \times$ $10^{11} \mathrm{AuNPs} / \mathrm{mL}$ and $5.5 \times 10^{11} \mathrm{AuNPs} / \mathrm{mL}$ caused approximately 2 -fold increase in p65 nuclear signals compared with control, $P<0.01$ (Figure 3(b)).

Nanogold did not stimulate micronuclei production (Figure 4(a)).

In contrast, the level of binucleated cells with micronuclei dropped after AuNP treatment, $P<0.01$ and $P<0.001$ (Figure 4(a)). We also investigated AuNP-mediated formation of 53 binding protein (53BP1) foci, which are considered to be accumulated at site of double strand breaks (DSBs) being a part of DNA repair process. Surprisingly, an inverse correlation between 53BP1 foci and micronuclei generation was observed (Figure 4(b)). Treatments with $1.1 \times$ $10^{11}$ AuNPs/mL and $5.5 \times 10^{11}$ AuNPs/mL caused a 2 - and 2.75 -fold increase in the formation of 53BP1 foci compared with control, respectively (Figure 4(b)).

\section{Discussion}

As data on nanoparticle (NP) effects in the brain, especially AuNP action on human astrocytes, are limited [21, 22], we decided to investigate astrocyte response to nanogold treatment. A range of AuNP concentrations from 1.4 to $700 \mathrm{ng} / \mathrm{mL}$ $\left(1.1 \times 10^{9}-5.5 \times 10^{11}\right.$ particles $\left./ \mathrm{mL}\right)$ was selected on the basis of previously published results on AuNP-mediated toxic effects on diverse mammalian cell lines, namely, PK-15 (porcine kidney), Vero (African green monkey kidney), NIH3T3 (mouse embryonic fibroblast), and MRC5 (human normal lung fibroblast) cells [14]. Nanogold-associated adaptive response without cytotoxicity was observed, which was mediated by increased ROS levels, activation of NF- $\kappa \mathrm{B}$ pathway, and robust 53BP1 recruitment resulting in genomic stability.

Our data on limited AuNP cytotoxicity against astrocyte cells are in agreement with previously reported results using primary mixed neural cell culture as a model [22]. Nanogold when used up to $100 \mu \mathrm{g} / \mathrm{mL}$ did not provoke toxic effects against neurons and astrocytes [22]. Moreover, AuNPs $\left(10^{9}\right.$ particles $\left./ \mathrm{mL}\right)$ were not cytotoxic and did not induce apoptotic cell death in N9 murine microglia and SHSY5Y human neuroblastoma cells [21]. In contrast, nanogold affected the astrocyte cell cycle leading to the arrest at the G2/ $M$ phase of the cell cycle, which may reflect a stress response. Nanogold ( $\geq 180 \mathrm{ng} / \mathrm{mL}$ ) also caused a significant delay of the G2/M phase of lung fibroblast cell cycle [14]. The inhibition of cell proliferation without causing cell death may allow the cell to alleviate the effects of stress stimuli. Indeed, the suppression of MRC5 cell proliferation and resistance to nanogoldinduced cyto- and genotoxicity was mediated by the activation of pathways involved in DNA damage response and repair, cell cycle regulation, and redox homeostasis, as well as ABC transporters [14].

Nanogold also induced senescence-associated $\beta$-galactosidase activity in human astrocytes, which is a sign of stressinduced premature senescence (SIPS) and may contribute to AuNP-mediated inhibition of cell proliferation [27]. More recently, nanodiamond powder was also shown to be an inducer of SIPS in human cervical cancer cells [26].

Nanogold stimulated reactive oxygen species (ROS) production in human astrocytes, which may be both related and not related to AuNP-induced cellular senescence. Indeed, the role of ROS in the cellular metabolism is much more complex than previously thought $[28,29]$. Of course, when the level of ROS is high, the impairment of redox homeostasis may lead to oxidative protein and DNA damage and a concomitant apoptotic/necrotic cell death. However, ROS at the moderate levels are considered molecular secondary messengers regulating cellular signaling pathways [30]. ROS may modulate redox reactions affecting active sites of enzymes and 


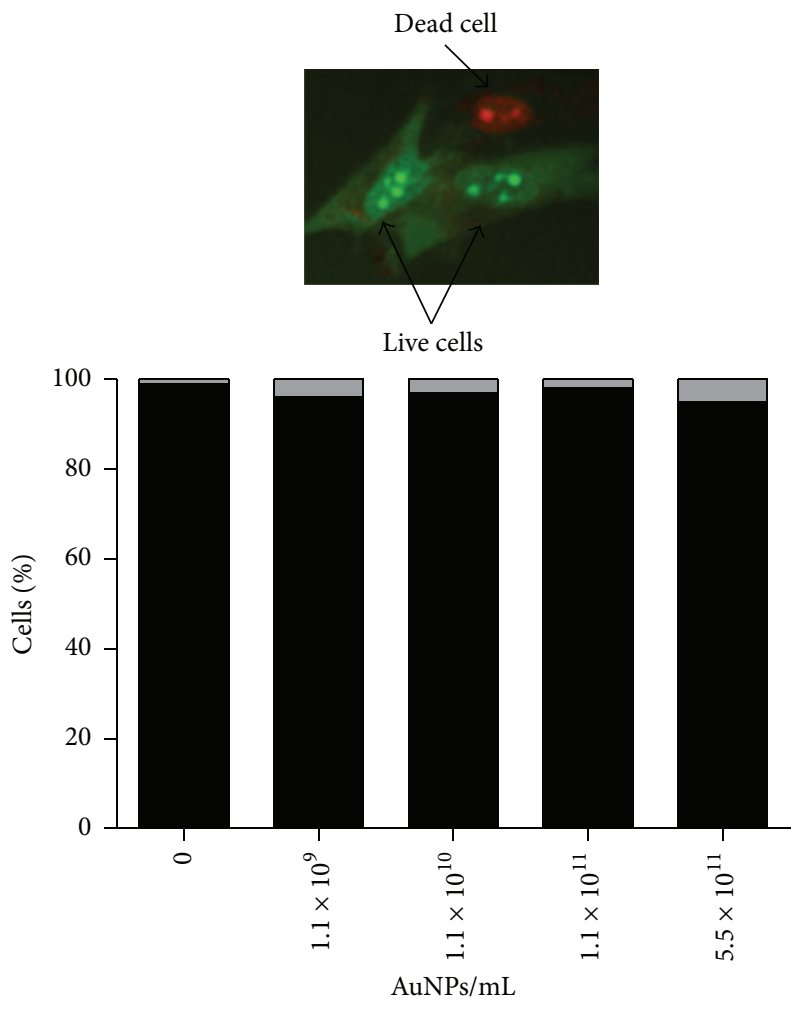

$\square$ Dead

Live

(a)

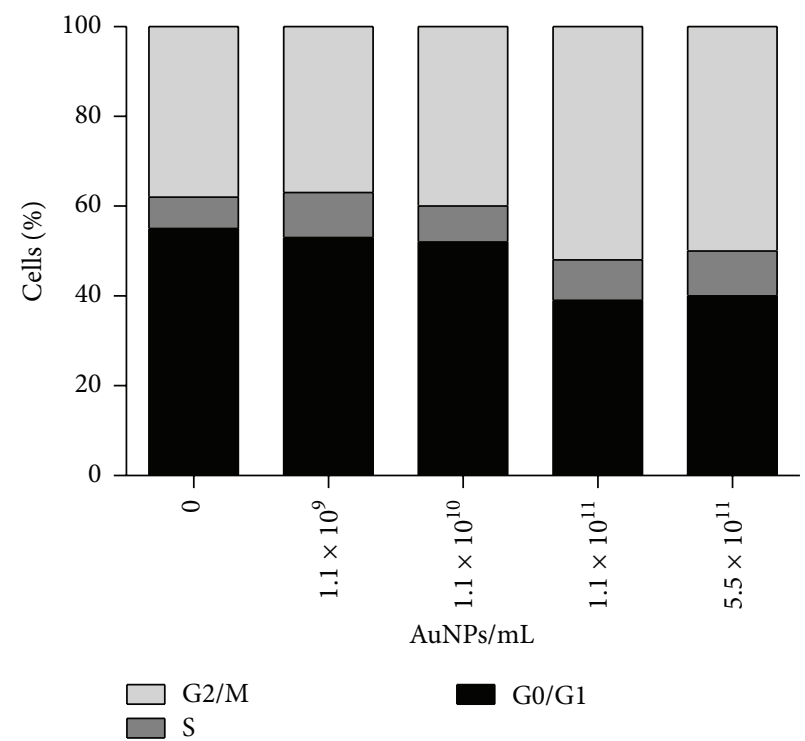

(b)

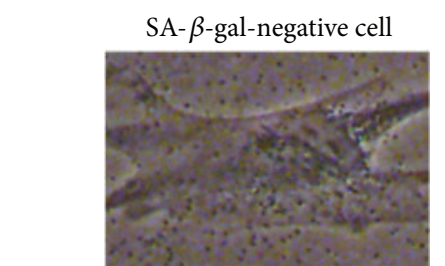

SA- $\beta$-gal-positive cell

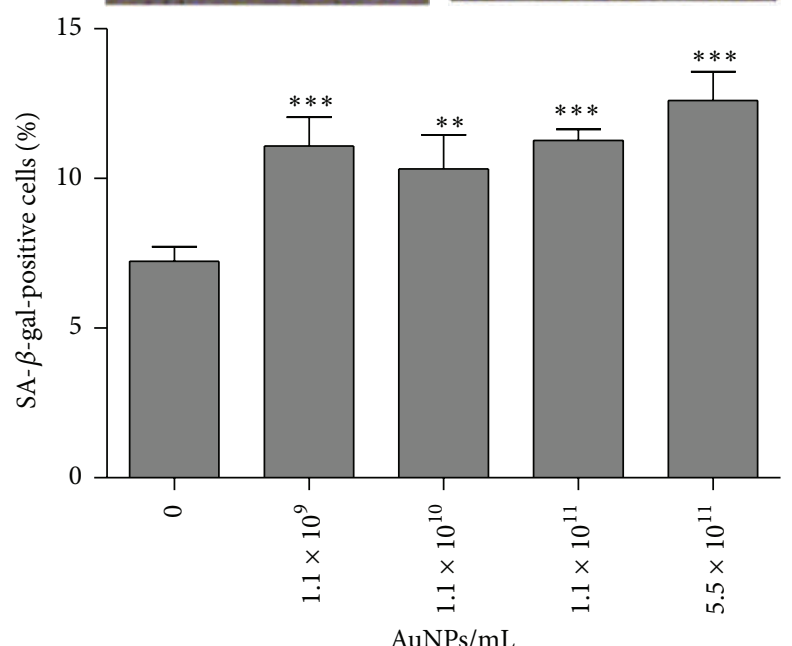

(c)

FIGURE 2: Nanogold-mediated cytotoxicity (a), changes in the cell cycle (b), and ability to induce stress-induced premature senescence (SIPS) (c). Human astrocytes were treated with $1.1 \times 10^{9}-5.5 \times 10^{11}$ AuNPs/mL for 96 h. (a) Cell viability was assessed using acridine orange-ethidium bromide staining. Arrows indicate live cells (green) and a dead cell (red). (b) Cell cycle analysis using an In Cell Analyzer 2000 (GE Healthcare, UK). (c) SIPS was assessed as SA- $\beta$-gal activity. The bars indicate the SD, $n=3,{ }^{* * *} P<0.001$, and ${ }^{* *} P<0.01$ compared with control (ANOVA and Dunnett's a posteriori test). Typical micrographs showing a SA- $\beta$-gal-positive cell and a SA- $\beta$-gal-negative cell are also presented. 


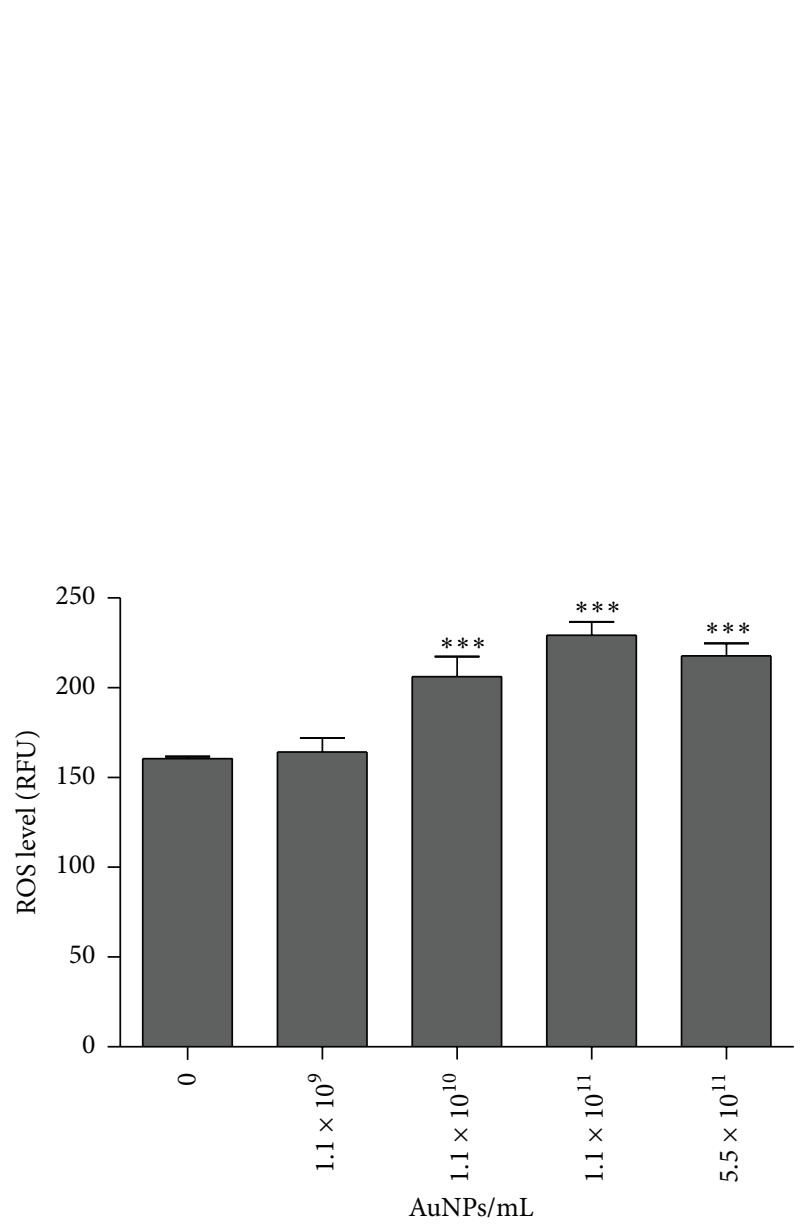

(a)

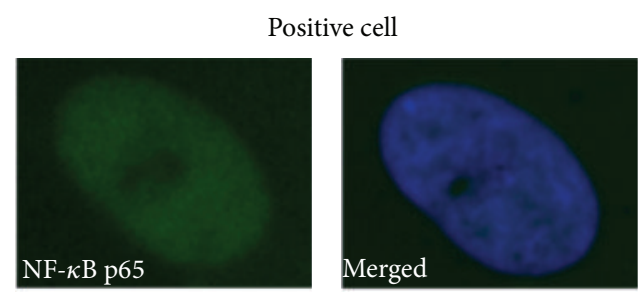

Negative cell

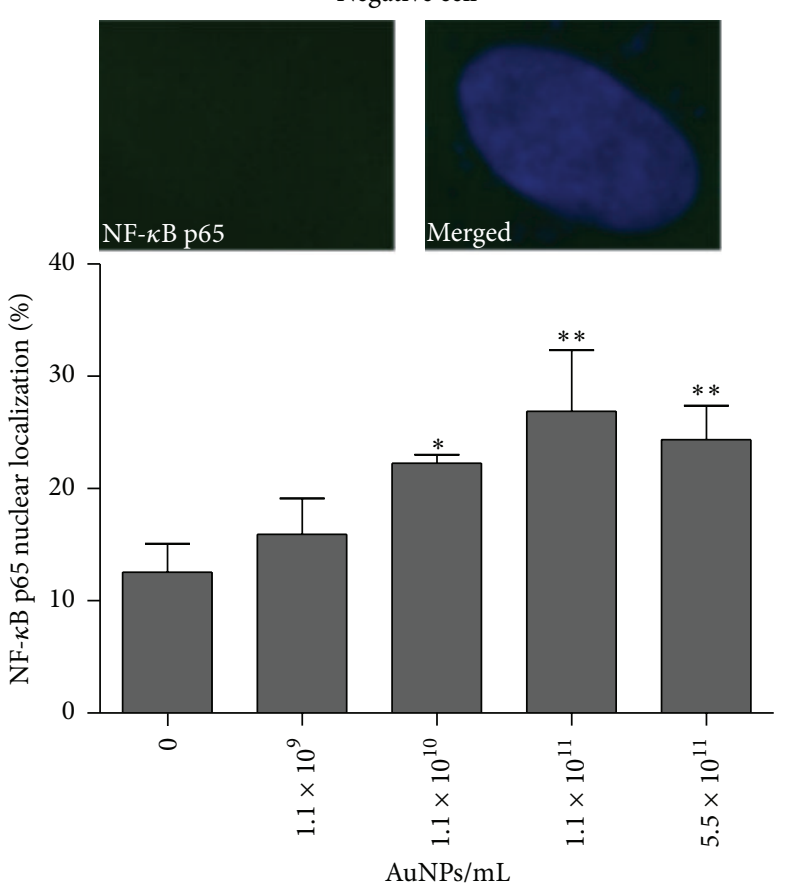

(b)

FIGURE 3: Nanogold-induced oxidative stress (a) and NF- $\kappa$ B activation (b). Human astrocytes were treated with $1.1 \times 10^{9}-5.5 \times 10^{11}$ AuNPs $/ \mathrm{mL}$ for $96 \mathrm{~h}$. (a) The steady-state level of reactive oxygen species (ROS) was measured using $2^{\prime}, 7^{\prime}$-dichlorodihydrofluorescein diacetate $\left(\mathrm{H}_{2} \mathrm{DCF}-\right.$ $\mathrm{DA})$ and imaging cytometry. The level of ROS is presented as relative fluorescence units (RFUs). The bars indicate the $\mathrm{SD}, n=3,{ }^{* * *} P<0.001$ compared with control (ANOVA and Dunnett's a posteriori test). (b) After AuNP treatment, NF- $\kappa$ B p65 was translocated into nucleus (green). Nuclei were visualized with Hoechst 33342 (blue). The bars indicate the SD, $n=3,{ }^{* *} P<0.01$, and ${ }^{*} P<0.05$ compared with control (ANOVA and Dunnett's a posteriori test).

the activity of transcription factors, such as NF- $\kappa \mathrm{B}$, JUN, and FOS [31]. After treatment with $20 \mu \mathrm{g} / \mathrm{kg}$ body weights of gold nanoparticles for 3 days, the levels of lipid peroxidation and oxidative DNA damage, and Hsp70, IFN- $\gamma$, and caspase 3 were increased, whereas the activity of glutathione peroxidase was decreased in rat brain [23]. The authors concluded that nanogold treatment may result in inflammation and DNA damage/cell death [23]. Nanogold $(20 \mu \mathrm{g} / \mathrm{mL})$ and nanosilver $(20 \mu \mathrm{g} / \mathrm{mL})$ stimulated ROS production in neurons and astrocytes, but the effect of AgNPs was 5fold stronger than the effect of AuNPs and contrarily to AgNPs, AuNPs did not provoke cytotoxicity [22]. AuNPs also decreased reduced glutathione (GSH) pools in N9 murine microglia and SH-SY5Y human neuroblastoma cells without causing cytotoxicity and apoptosis [21]. As increased ROS level was not accompanied by astrocyte cell death, we decided to evaluate whether nanogold-associated imbalanced redox homeostasis may affect redox-sensitive transcription factor
NF- $\kappa$ B. Indeed, AuNP treatment resulted in increased nuclear p65 signals, which is in agreement with the view that $\mathrm{NF}-\kappa \mathrm{B}$ is the sensor of oxidative stress and its regulation is redox-based [32, 33]. NF- $\kappa$ B is a dimeric transcription factor composed of different members of the Rel family, such as $\mathrm{p} 65$ (RelA), p50, p52, c-Rel, and RelB and the mammalian NF$\kappa \mathrm{B}$ protein family includes five members: NF- $\kappa \mathrm{B} 1$ (p50/p105), NF- $\kappa$ B2 (p52/p100), RelA (p65), RelB, and c-Rel [34]. Upon activation, NF- $\kappa$ B is rapidly released from the complex of NF$\kappa \mathrm{B} / \mathrm{NF}-\kappa \mathrm{B}$ inhibitor and translocated into the nucleus where a group of NF- $\kappa$ B-responsive effector genes involved in stress responses, inflammation, cell proliferation, and apoptosis can be regulated [35]. It is believed that NF- $\kappa \mathrm{B}$ activation promotes cell survival and exerts antiapoptotic effects [36, 37]. More recently, AuNPs were found to be an activator of NF- $\kappa$ B in murine B lymphocyte cell line (CH12.LX) [38]. Nanogold induced activation of the canonical NF- $\kappa \mathrm{B}$ signaling pathway as evidenced by $\mathrm{I} \kappa \mathrm{B} \alpha$ phosphorylation at serine residues 32 


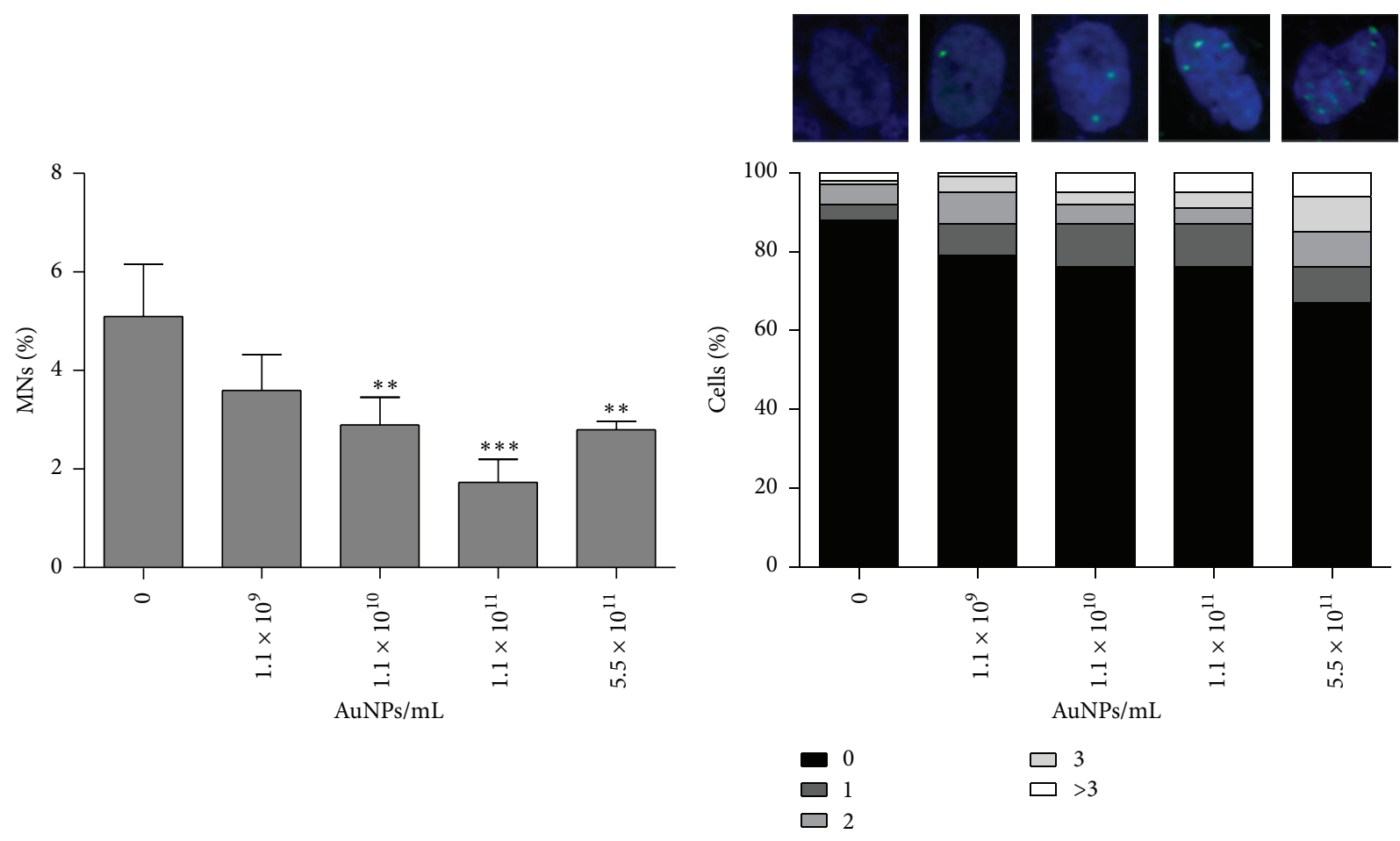

(a)

(b)

FIGURE 4: The effect of nanogold on micronuclei production (a) and 53BP1 recruitment (b). Human astrocytes were treated with $1.1 \times 10^{9}-5.5 \times$ $10^{11}$ AuNPs/mL for $96 \mathrm{~h}$. (a) The cytokinesis-block micronucleus (CBMN) assay. The bars indicate the SD, $n=3,{ }^{* * *} P<0.001$, and ${ }^{* *} P<0.01$ compared with control (ANOVA and Dunnett's a posteriori test). (b) 53BP1 foci were revealed using 53BP1 immunostaining. Cells with 0, 1, 2,3 , and more than $353 \mathrm{BP} 1$ foci were scored [\%].

and 36 followed by $\mathrm{I} \kappa \mathrm{B} \alpha$ degradation and increased nuclear RelA (p65), which, in turn, resulted in altered B lymphocyte function (i.e., increased antibody expression) [38].

Nanogold was reported to promote genotoxicity and DNA damage response in different cell types in vitro and in vivo $[14,23,39,40]$. In the AuNP treated lung fibroblasts ( $72 \mathrm{~h}$ exposure time, $1 \mathrm{nM}$ AuNPs), genotoxic events were observed and the level of several proteins was affected including oxidative stress related proteins (NADH ubiquinone oxidoreductase (NDUFS1), protein disulfide isomerase associate 3 (PDIA3), heterogeneous nuclear ribonucleoprotein $\mathrm{Cl} / \mathrm{C} 2$ (hnRNP C1/C2), and thioredoxin-like protein 1 (TXNL1)), as well as proteins associated with cell cycle regulation, cytoskeleton, and DNA repair (heterogeneous nuclear ribonucleoprotein $\mathrm{C} 1 / \mathrm{C} 2$ (hnRNP $\mathrm{Cl} / \mathrm{C} 2$ ) and secernin-1 (SCN1)) [40]. The authors concluded that AuNP treatment can induce oxidative stress-mediated genomic instability [40]. More recently, similar genomic response was observed in lung fibroblasts [14]. After $360 \mathrm{ng} / \mathrm{mL}$ AuNP treatment, the expression of genes involved in DNA damage response, repair pathways, and redox homeostasis was increased (e.g., the tumor suppressor $p 53$ and $B R C A 1$ genes, genes involved in base-excision respire (BER) and homologous recombination pathways, genes associated with mismatch repair and translesion synthesis: MLH3 and Rev1, and genes encoding glutathione reductase, glutathione transferase, and glutaredoxin 2) [14]. However, the authors suggested that such response may contribute to resistance to AuNP-induced cyto- and genotoxicity [14]. Data on nanogold-induced genotoxic stress in human astrocytes are lacking. We showed for the first time that AuNPs did not provoke genotoxicity in human astrocytes by means of the cytokinesis-block micronucleus (CBMN) assay. In contrast, the robust recruitment of 53BP1 was observed. During cellular response to DNA damage, p53 binding protein- (53BP1-) dependent pathway is activated: $53 \mathrm{BP} 1$ is recruited to sites of DNA damage due to methylation state-specific recognition of histone $\mathrm{H} 4-\mathrm{K} 20$ by $53 \mathrm{BP} 1$ [41]. 53BP1 was shown to be involved in the regulation of activation of the G2/M phase checkpoint, the intra-S phase checkpoint, and repair of DNA double strand breaks (DSBs) via nonhomologous end-joining (NHEJ) [42-45]. A link between recruitment of 53BP1 and resolution of DNA damage has been previously established [46]. In 53BP1-depleted WI38 human fibroblasts exposed to agents causing DNA damage, the fraction of micronuclei-positive cells was elevated [46]. Additionally, enhanced activation or upregulation of 53BP1 resulted in lower level of chromosomal damage as a response to DNA damage [46]. Thus, 53BP1 contributed to genomic stability in human fibroblasts [46]. Perhaps, the robust recruitment of 53BP1 may also result in reduced micronuclei production after astrocyte treatment with gold nanoparticles.

In conclusion, we showed for the first time that nanogold may trigger adaptive response in human astrocytes, which was mediated by oxidant-based activation of NF- $\kappa \mathrm{B}$ and 
53BP1 recruitment promoting cell survival and resistance to nanogold-mediated genotoxicity.

\section{Conflict of Interests}

The authors declare that they have no conflict of interests.

\section{Authors' Contribution}

Jennifer Mytych (a graduate student) performed the experiments and analyzed the data. Anna Lewinska carried out data interpretation and wrote the paper. Jacek Zebrowski performed the experiments and analyzed the data. Maciej Wnuk carried out data interpretation and conceived and designed the experiments.

\section{Acknowledgment}

This study was supported by the Innovative Economy Operational Programme 2007-2013 MNISW 19/POIG/GP/2013.

\section{References}

[1] N. Khlebtsov and L. Dykman, "Biodistribution and toxicity of engineered gold nanoparticles: a review of in vitro and in vivo studies," Chemical Society Reviews, vol. 40, no. 3, pp. 1647-1671, 2011.

[2] R. A. Sperling, P. Rivera Gil, F. Zhang, M. Zanella, and W. J. Parak, "Biological applications of gold nanoparticles," Chemical Society Reviews, vol. 37, no. 9, pp. 1896-1908, 2008.

[3] P. Ghosh, G. Han, M. De, C. K. Kim, and V. M. Rotello, "Gold nanoparticles in delivery applications," Advanced Drug Delivery Reviews, vol. 60, no. 11, pp. 1307-1315, 2008.

[4] J. R. Kanwar, X. Sun, V. Punj et al., "Nanoparticles in the treatment and diagnosis of neurological disorders: untamed dragon with fire power to heal," Nanomedicine: Nanotechnology, Biology, and Medicine, vol. 8, no. 4, pp. 399-414, 2012.

[5] R. Gromnicova, H. A. Davies, P. Sreekanthreddy et al., "Glucose-coated gold nanoparticles transfer across human brain endothelium and enter astrocytes in vitro," PLoS ONE, vol. 8, no. 12, Article ID e81043, 2013.

[6] S. Wohlfart, S. Gelperina, and J. Kreuter, "Transport of drugs across the blood-brain barrier by nanoparticles," Journal of Controlled Release, vol. 161, no. 2, pp. 264-273, 2012.

[7] E. E. Connor, J. Mwamuka, A. Gole, C. J. Murphy, and M. D. Wyatt, "Gold nanoparticles are taken up by human cells but do not cause acute cytotoxicity," Small, vol. 1, no. 3, pp. 325-327, 2005.

[8] A. M. Alkilany and C. J. Murphy, "Toxicity and cellular uptake of gold nanoparticles: what we have learned so far?" Journal of Nanoparticle Research, vol. 12, no. 7, pp. 2313-2333, 2010.

[9] G. Oberdörster, A. Elder, and A. Rinderknecht, "Nanoparticles and the brain: cause for concern?" Journal of Nanoscience and Nanotechnology, vol. 9, no. 8, pp. 4996-5007, 2009.

[10] Y. Pan, S. Neuss, A. Leifert et al., "Size-dependent cytotoxicity of gold nanoparticles," Small, vol. 3, no. 11, pp. 1941-1949, 2007.

[11] Q. Zhang, V. M. Hitchins, A. M. Schrand, S. M. Hussain, and P. L. Goering, "Uptake of gold nanoparticles in murine macrophage cells without cytotoxicity or production of proinflammatory mediators," Nanotoxicology, vol. 5, no. 3, pp. 284295, 2011.
[12] K. B. Male, B. Lachance, S. Hrapovic, G. Sunahara, and J. H. T. Luong, "Assessment of cytotoxicity of quantum dots and gold nanoparticles using cell-based impedance spectroscopy," Analytical Chemistry, vol. 80, no. 14, pp. 5487-5493, 2008.

[13] C. J. Gannon, C. R. Patra, R. Bhattacharya, P. Mukherjee, and S. A. Curley, "Intracellular gold nanoparticles enhance non-invasive radiofrequency thermal destruction of human gastrointestinal cancer cells," Journal of Nanobiotechnology, vol. 6, article 2, 2008.

[14] P. J. Chueh, R.-Y. Liang, Y.-H. Lee, Z.-M. Zeng, and S.-M. Chuang, "Differential cytotoxic effects of gold nanoparticles in different mammalian cell lines," Journal of Hazardous Materials, vol. 264, pp. 303-312, 2014.

[15] S.-M. Chuang, Y.-H. Lee, R.-Y. Liang et al., "Extensive evaluations of the cytotoxic effects of gold nanoparticles," Biochimica et Biophysica Acta: General Subjects, vol. 1830, no. 10, pp. 49604973, 2013.

[16] Y. Pan, A. Leifert, D. Ruau et al., "Gold nanoparticles of diameter $1.4 \mathrm{~nm}$ trigger necrosis by oxidative stress and mitochondrial damage," Small, vol. 5, no. 18, pp. 2067-2076, 2009.

[17] R. Coradeghini, S. Gioria, C. P. García et al., "Size-dependent toxicity and cell interaction mechanisms of gold nanoparticles on mouse fibroblasts," Toxicology Letters, vol. 217, no. 3, pp. 205216, 2013.

[18] T. Mironava, M. Hadjiargyrou, M. Simon, V. Jurukovski, and M. H. Rafailovich, "Gold nanoparticles cellular toxicity and recovery: effect of size, concentration and exposure time," Nanotoxicology, vol. 4, no. 1, pp. 120-137, 2010.

[19] M. F. Rahman, J. Wang, T. A. Patterson et al., "Expression of genes related to oxidative stress in the mouse brain after exposure to silver-25 nanoparticles," Toxicology Letters, vol. 187, no. 1, pp. 15-21, 2009.

[20] E. Söderstjerna, P. Bauer, T. Cedervall et al., "Silver and gold nanoparticles exposure to in vitro cultured retina-studies on nanoparticle internalization, apoptosis, oxidative stress, glialand microglial activity," PLOS ONE, vol. 9, no. 8, Article ID e105359, 2014.

[21] F. Koch, A.-M. Möller, M. Frenz, U. Pieles, K. KuehniBoghenbor, and M. Mevissen, "An in vitro toxicity evaluation of gold-, PLLA- and PCL-coated silica nanoparticles in neuronal cells for nanoparticle-assisted laser-tissue soldering," Toxicology in Vitro, vol. 28, no. 5, pp. 990-998, 2014.

[22] A. Haase, S. Rott, A. Mantion et al., "Effects of silver nanoparticles on primary mixed neural cell cultures: uptake, oxidative stress and acute calcium responses," Toxicological Sciences, vol. 126, no. 2, pp. 457-468, 2012.

[23] N. J. Siddiqi, M. A. K. Abdelhalim, A. K. El-Ansary, A. S. Alhomida, and W. Y. Ong, "Identification of potential biomarkers of gold nanoparticle toxicity in rat brains," Journal of Neuroinflammation, vol. 9, article 123, 2012.

[24] N. Dworak, M. Wnuk, J. Zebrowski, G. Bartosz, and A. Lewinska, "Genotoxic and mutagenic activity of diamond nanoparticles in human peripheral lymphocytes in vitro," Carbon, vol. 68, pp. 763-776, 2014.

[25] A. Lewinska, J. Adamczyk, J. Pajak et al., "Curcumin-mediated decrease in the expression of nucleolar organizer regions in cervical cancer (HeLa) cells," Mutation Research, vol. 771, pp. 43-52, 2014.

[26] J. Mytych, A. Lewinska, A. Bielak-Zmijewska, W. Grabowska, J. Zebrowski, and M. Wnuk, "Nanodiamond-mediated impairment of nucleolar activity is accompanied by oxidative stress 
and DNMT2 upregulation in human cervical carcinoma cells," Chemico-Biological Interactions, vol. 220, pp. 51-63, 2014.

[27] G. P. Dimri, X. Lee, G. Basile et al., "A biomarker that identifies senescent human cells in culture and in aging skin in vivo," Proceedings of the National Academy of Sciences of the United States of America, vol. 92, no. 20, pp. 9363-9367, 1995.

[28] J. P. D. Magalhães and G. M. Church, "Cells discover fire: employing reactive oxygen species in development and consequences for aging," Experimental Gerontology, vol. 41, no. 1, pp. 1-10, 2006.

[29] G. Bartosz, "Reactive oxygen species: destroyers or messengers?” Biochemical Pharmacology, vol. 77, no. 8, pp. 1303-1315, 2009.

[30] F. Esposito, R. Ammendola, R. Faraonio, T. Russo, and F. Cimino, "Redox control of signal transduction, gene expression and cellular senescence," Neurochemical Research, vol. 29, no. 3, pp. 617-628, 2004.

[31] J. Remacle, M. Raes, O. Toussaint, P. Renard, and G. Rao, "Low levels of reactive oxygen species as modulators of cell function," Mutation Research/DNAging, vol. 316, no. 3, pp. 103-122, 1995.

[32] N. Li and M. Karin, "Is NF-kappaB the sensor of oxidative stress?” The FASEB Journal, vol. 13, no. 10, pp. 1137-1143, 1999.

[33] Y. Kabe, K. Ando, S. Hirao, M. Yoshida, and H. Handa, "Redox regulation of NF- $\kappa \mathrm{B}$ activation: distinct redox regulation between the cytoplasm and the nucleus," Antioxidants and Redox Signaling, vol. 7, no. 3-4, pp. 395-403, 2005.

[34] P. A. Baeuerle and D. Baltimore, "Nf- $\kappa$ B: ten years after," Cell, vol. 87, no. 1, pp. 13-20, 1996.

[35] T. Wang, X. Zhang, and J. J. Li, "The role of NF- $\kappa \beta$ in the regulation of cell stress responses," International Immunopharmacology, vol. 2, no. 11, pp. 1509-1520, 2002.

[36] M. Barkett and T. D. Gilmore, "Control of apoptosis by Rel/NF$\kappa \mathrm{B}$ transcription factors," Oncogene, vol. 18 , no. 49, pp. 69106924, 1999.

[37] J. Kucharczak, M. J. Simmons, Y. Fan, and C. Gélinas, “To be, or not to be: NF-kappaB is the answer-role of Rel/NF-kappaB in the regulation of apoptosis," Oncogene, vol. 22, no. 56, pp. 89618982, 2003.

[38] M. Sharma, R. L. Salisbury, E. I. Maurer, S. M. Hussain, and C. E. W. Sulentic, "Gold nanoparticles induce transcriptional activity of NF- $\kappa$ B in a B-lymphocyte cell line," Nanoscale, vol. 5, no. 9, pp. 3747-3756, 2013.

[39] I. M. M. Paino, V. S. Marangoni, C. de Oliveira Rde, L. M. G. Antunes, and V. Zucolotto, "Cyto and genotoxicity of gold nanoparticles in human hepatocellular carcinoma and peripheral blood mononuclear cells," Toxicology Letters, vol. 215, no. 2, pp. 119-125, 2012.

[40] J. J. Li, S.-L. Lo, C.-T. Ng et al., "Genomic instability of gold nanoparticle treated human lung fibroblast cells," Biomaterials, vol. 32, no. 23, pp. 5515-5523, 2011.

[41] M. V. Botuyan, J. Lee, I. M. Ward et al., "Structural basis for the methylation state-specific recognition of histone $\mathrm{H} 4-\mathrm{K} 20$ by 53BP1 and Crb2 in DNA repair," Cell, vol. 127, no. 7, pp. 13611373, 2006.

[42] R. A. DiTullio Jr., T. A. Mochan, M. Venere et al., "53BP1 functions in a ATM-dependent checkpoint pathway that is constitutively activated in human cancer," Nature Cell Biology, vol. 4, no. 12, pp. 998-1002, 2002.

[43] B. Wang, S. Matsuoka, P. B. Carpenter, and S. J. Elledge, "53BP1, a mediator of the DNA damage checkpoint," Science, vol. 298, no. 5597, pp. 1435-1438, 2002.
[44] J. Silverman, H. Takai, S. B. C. Buonomo, F. Eisenhaber, and T. de Lange, "Human Rif1, ortholog of a yeast telomeric protein, is regulated by ATM and 53BP1 and functions in the S-phase checkpoint," Genes and Development, vol. 18, no. 17, pp. 21082119, 2004.

[45] S. Difilippantonio, E. Gapud, N. Wong et al., "53BP1 facilitates long-range DNA end-joining during $\mathrm{V}(\mathrm{D}) \mathrm{J}$ recombination," Nature, vol. 456, no. 7221, pp. 529-533, 2008.

[46] L. S. Fink, M. Roell, E. Caiazza et al., "53BP1 contributes to a robust genomic stability in human fibroblasts," Aging, vol. 3, no. 9, pp. 836-845, 2011. 

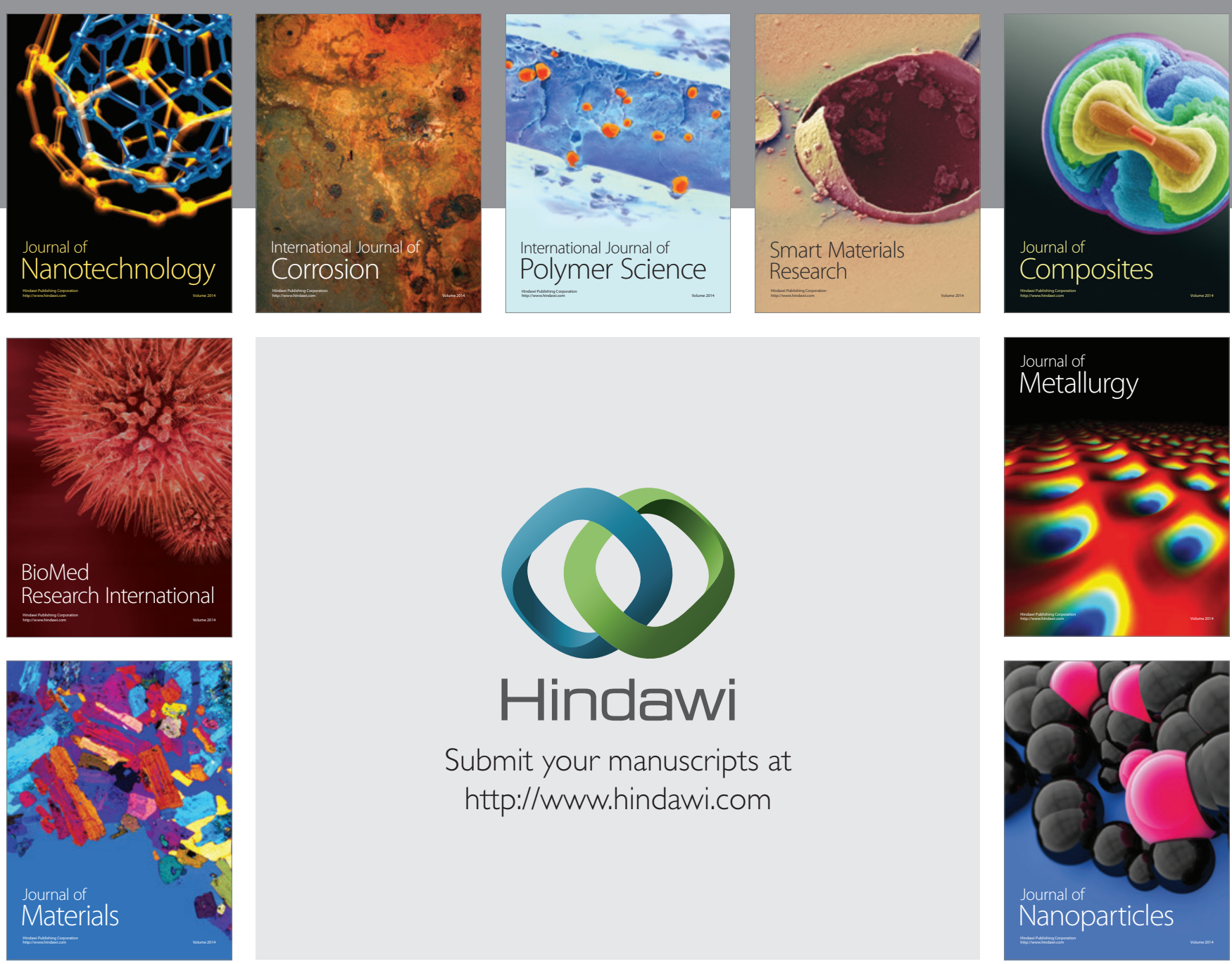

Submit your manuscripts at http://www.hindawi.com
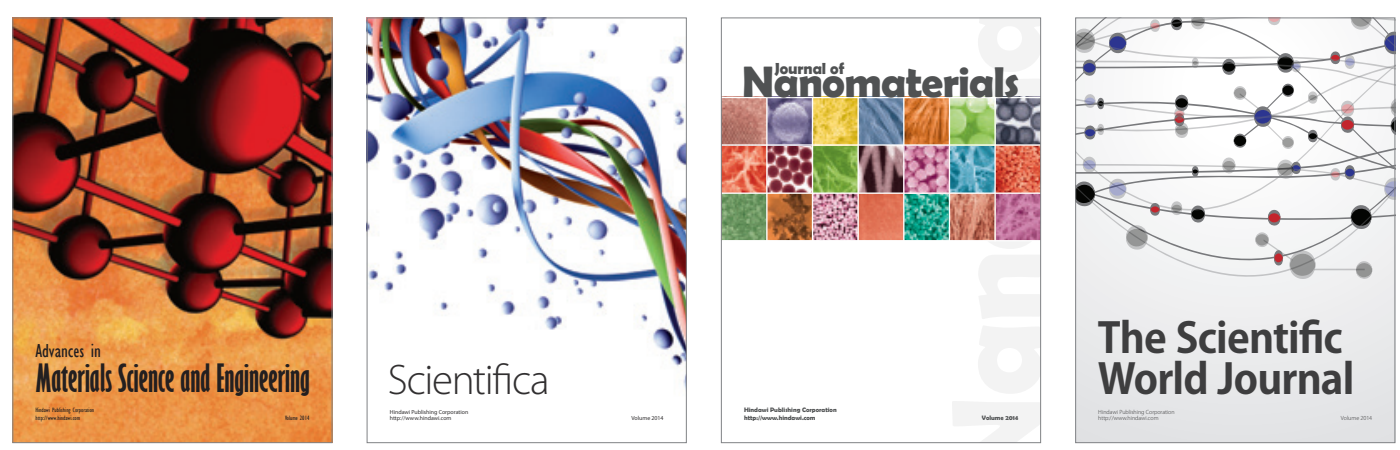

\section{The Scientific World Journal}
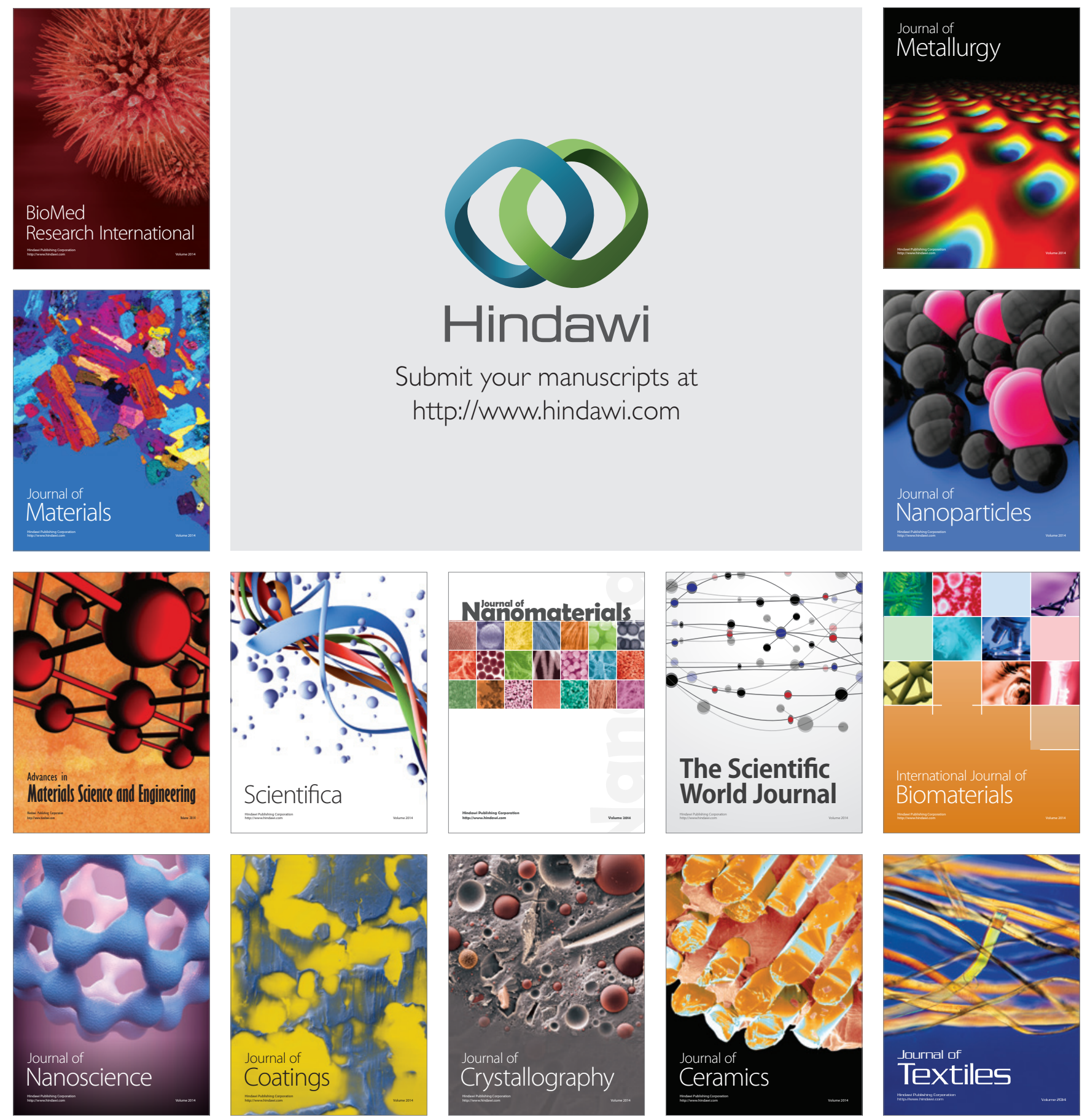